\title{
Pengembangan Sistem Informasi Layanan Bimbingan Akademik Mahasiswa
}

\author{
Missi Hikmatyar ${ }^{1}$, Yusuf Sumaryana ${ }^{2}$ \\ ${ }^{1}$ Universitas Perjuangan Tasikmalaya, Jl. PETA No.177, Tasikmalaya 46115 \\ ${ }^{2}$ Universitas Perjuangan Tasikmalaya, Jl. PETA No.177, Tasikmalaya 46115 \\ e-mail:missi@unper.ac.id ${ }^{* 1}$,yusufsumaryana@unper.ac.id ${ }^{2}$
}

\begin{tabular}{|c|c|}
\hline INFORMASI ARTIKEL & \\
\hline $\begin{array}{l}\text { Sejarah Artikel: } \\
\text { Diterima Redaksi : - } \\
\text { Revisi Akhir : - } \\
\text { Diterbitkan Online : - }\end{array}$ & \multirow{4}{*}{$\begin{array}{l}\text { Layanan bimbingan akademik maupun non akademik sangat penting untuk kemajuan } \\
\text { pada tiap individu mahasiswa. Layanan bimbingan berpengaruh pada motivasi belajar } \\
\text { mahasiswa dan peningkatan Indeks Prestasi mahasiswa. Universitas Perjuangan } \\
\text { Tasikmalaya menyediakan layanan bimbingan bagi mahasiswa, namun berjalan tidak } \\
\text { efektif. Perlu ada rekam jejak bimbingan mahasiswa agar perkembangan bisa terkontrol } \\
\text { kearah yang lebih baik. Pengembangan sistem informasi layanan bimbingan merupakan } \\
\text { solusi dari permasalahan yang terkait dengan bimbingan akademik bagi mahasiswa } \\
\text { Universitas Perjuangan Tasikmalaya. Sistem informasi yang akan dikembangkan berbasis } \\
\text { web yang dapat diakses oleh dosen maupun mahasiswa dengan menggunakan bahasa } \\
\text { pemrograman PHP dan MySQL sebagai pangkalan data. Proses pengembangannya } \\
\text { meliputi beberapa tahap yaitu pertama, analisis kebutuhan adalah melakukan analisa } \\
\text { terhadap sistem yang sudah berjalan. Kedua, perancangan yaitu melakukan perancangan } \\
\text { awal atau mendesain sistem yang akan dibuat. Ketiga, implementasi yaitu melakukan } \\
\text { penerapan dengan melakukan coding terhadap desain yang telah dirancang. Keempat, } \\
\text { pengujian yaitu melakukan pengujian dengan sudut pandang pengembang sistem dan user } \\
\text { (dosen dan mahasiswa) untuk diuji kehandalannya. Kelima, maintanence yaitu } \\
\text { melakukan pemeliharan atau pengembangan lebih lanjut sesuai dengan kebutuhan sistem. }\end{array}$} \\
\hline $\begin{array}{l}\text { Kata Kunci: } \\
\text { Bimbingan, Akademik, Sistem, Informasi. }\end{array}$ & \\
\hline Korespondensi : & \\
\hline & \\
\hline
\end{tabular}

\section{PENDAHULUAN}

Pendidikan termasuk dalam Tri Dharma Perguruan Tinggi sebagai kewajiban seorang dosen untuk mendidik setiap mahasiswanya. Pendidikan merupakan komponen yang bersentuhan langsung dengan mahasiswa, dalam hal ini dosen melakukan pengajaran maupun melakukan layanan bimbingan terhadap mahasiswa. Menurut penelitian [1] layanan bantuan bimbingan bagi mahasiswa diperlukan untuk membantu mahasiswa mengembangkan kesejahteraannya terutama pada faktor Faktor diri esensial dan sosial dengan sub faktor spiritualitas, perawatan diri dan cinta. Layanan bimbingan berfungsi untuk memantau mahasiswanya agar lebih terarah dalam ruang lingkup akademis dan non akademik. Fungsi lain dari Layanan bimbingan adalah untuk memotivasi mahasiswa dalam belajar dan meningkatkan prestasi [2], [3]. Universitas Perjuangan Tasikmalaya melakukan usaha dalam pengembangan layanan bimbingan dengan membuat buku perwalian bagi dosen dan mahasiswa agar lebih terpantau. Perwalian dilaksanakan minimal tiga kali pertemuan dalam satu semester, namun masalah pertemuan berkala menjadi masalah bagi kelangsungan proses perwalian. Pertemuan berkala menjadi masalah karena tidak fleksibel dalam prosesnya serta batasan terhadap isi pertemuan yang hanya bersifat informasi formal. Mahasiswa tidak bebas dalam melakukan bimbingan yang bersifat privasi yang perlu penanganan intens.

Permasalahan terkait dengan fleksibelitas bimbingan dapat diatasi dengan pembuatan sistem informasi sebagai sarana layanan bimbingan tepat sasaran bagi setiap mahasiswa. Sistem informasi perlu dibuat agar dosen dan mahasiswa lebih intens dalam melakukan bimbingan formal maupun non formal. Sistem informasi membantu dosen maupun mahasiswa dalam melakukan bimbingan yang lebih efektif dan fleksibel. Permasalahan yang dialami mahasiswa dapat dapat langsung di sampaikan kepada dosen wali dengan respon yang lebih cepat dibandingkan dengan perwalian secara berkala. Respon cepat berdampak pada cepatnya penyelesaian masalah yang dialami oleh mahasiswa..

\section{TINJAUAN PUSTAKA}

Layanan bimbingan merupakan aspek penting pada perkembangan pendidikan di instansi pendidikan. Fungsi dari layanan bimbingan salah satunya adalah untuk memotivasi mahasiswa dalam belajar seperti pada penelitian Putro dkk yang mengungkapkan bahwa layanan bimbingan mempengaruhi motivasi belajar [2]. Pengaruh layanan bimbingan terhadap motivasi belajar diteliti juga oleh Pranoto [3] yang menggunakan metode Self Regulation pada kelompok mahasiswa. Pengingkatan motivasi belajar menghasilkan perkembangan pada potensi akademiknya dan meningkatkan prestasi [3].

Pengembangan sistem informasi layanan bimbingan akademik pernah dilakukan oleh Norhikmah [4] dengan membuat fitur chating menggunakan Asp.NET Signal $R$ untuk memonitor mahasiswa dan sebagai alat komunikasi antara mahasiswa dengan dosen wali. Pada 
penelitian lain, Ifdil dan Ardi melakukan penelitian tentang kebutuhan sistem elektonik konseling yang perlu diterapkan pada sistem informasi. Pada penelitiannya dijelaskan bahwa terdapat beberapa komponen yang perlu ada dalam sistem informasi layanan bimbingan diantaranya web, handphone, email, chat dan video conference [5]. Penelitian lain mengembangan aplikasi E-Counseling dengan menggunakan metode Backward Chaining untuk membantu siswa yang terisolir, untuk mengenal dan menerima dirinya, mengenal dan menerima lingkungannya secara positif dan dinamis, serta mengambil keputusan mengarahkan dan mewujudkan diri secara efektif dan produktif sesuai dengan dirinya [6].

Sistem informasi yang akan dibuat menggunakan pangkalan data MySQL sebagaimana penelitian Handayani dan Putri [7] yang merancang sebuah basis data instrument bimbingan konseling sebagai alat ungkap pemahaman diri siswa. Penelitian lain yang mengembangkan sistem informasi layanan bimbingan dengan MySQL adalah Noviana dkk. Pada penelitiannya dilakukan perancangan sistem informasi bimbingan tugas akhir bagi mahasiwa berbasis web dan pangkalan data menggunakan MySQL [8]. Sistem informasi yang akan dirancang menggunakan bahasa pemrograman PHP. PHP merupakan bahasa pemrograman yang digunakan untuk membuat sistem berbasis web. Pada penelitian Riswandha dilakukan perancangan sistem informasi konseling dengan menggunakan bahasa pemrograman PHP [6]. Penelitian lain terkait dengan pengembangan sistem informasi adalah penelitian tentang sistem pakar konseling dan psikoterapi masalah kepribadian dramatic dengan metode forward chaining dengan menggunakan bahasa pemrograman PHP dan pangkalan data MySQL [9].

Metode yang dipakai dalam pengembangan sistem adalah System Development Life Cycle (SDLC). Metode SDLC dipakai dalam pengembangan aplikasi bimbingan dan konseling mahasiswa menggunakan pendekatan model diagram alir data untuk mempermudah konselor dalam menyikapi konseling karena sudah terdapat laporan data pelanggaran mahasiswa dan data hasil konseling yang dilengkapi informasi mengenai metode yang digunakan selama konseling [10]. Penelitian lain yang menggunakan metode SDLC adalah pembuatan aplikasi media informasi sekolah berbasis SMS Gateway untuk memberikan kemudahan informasi siswa di sekolah [11].

\section{METODOLOGI}

Penelitian ini menggunakan metode pengembangan System Development Life Cycle (SDLC) dengan langkah-langkah sebagai berikut :

\subsection{Analisis}

Tahap analisis merupakan langkah pertama dalam penelitian yang mencakup analisis permasalahan yang terjadi, analisis kebutuhan data dan tool. Analisis kebutuhan tool atau alat terdiri dari dua yaitu analisis kebutuhan hardware, analisis kebutuhan software dan analisis kebutuhan brainware.

\subsection{Perancangan}

Perancangan merupakan tahap mendesain sistem yang akan dibuat sesuai dengan kebutuhan-kebutuhan yang telah di analisa sebelumnya. Tahap perancangan meliputi pembuatan desain interface, bagan alur sistem dengan menggunakan Unified Modelling Language (UML).

\subsection{Implementasi}

Tahap implementasi merupakan tahapan setelah dibuat rancangan sistem. Pada tahap implementasi dilakukan penerapan berbentuk coding untuk mengasilkan sistem informasi dengan menggunakan PHP sebagai bahasa pemrograman dan MySQL sebagai pangkalan data.

\subsection{Pengujian}

Tahapan pengujian adalah tahapan melakukan uji coba pada sistem informasi yang sudah diimplementasi untuk di uji kehandalannya. Pengujian yang dilakukan menggunakan metode pengujian Blackbox atau pengujian pada fungsi sistem yang telah di implementasikan

\subsection{Pemeliharaan}

Tahap pemeliharaan merupakan tahapan pengembangan sistem informasi selanjutnya atau melakukan upgrading pada sistem yang telah dirancang sesuai dengan kebutuhan agar dapat digunakan secara kontinu.

\section{PEMBAHASAN}

\subsection{Analisis}

Tahap awal dalam pembuatan sistem yaitu melakukan analisa sistem yang sedang berjalan. Pada tahap analisa sistem dihasilkan bahwa sistem layanan bimbingan akademik di Universitas Perjuangan Tasikmalaya masih menggunakan buku manual dalam melakukan bimbingan. Menurut hasil analisis sistem yang akan dibangun menggunakan panduan akademik perguruan tinggi. Adapun panduan akademik yang dijadikan acuan dalam pembuatan sistem informasi adalah sebagai berikut:

\subsubsection{Waktu pembimbingan}

1) Pada awal Semester

Sebelum mahasiswa melaksanakan KRS online, pembimbing akademik berkewajiban melaksanakan tugas bimbingan pada waktu dan tempat yang telah dijadwalkan dengan : 
a. Memberikan bimbingan perencanaan studi dalam 1 semester

b. Memastikan jenis matakuliah yang diambil mahasiswa dalam semester yang bersangkutan berdasarkan IP yang diperoleh pada semester lalu

c. Memastikan semua mahasiswa bimbingan sudah melakukan KRS online dengan mencermati pada http//unper.ac.id.

d. Menghubungi mahasiswa yang belum melakukan KRS online atau belum mengoptimalkan pengambilan jumlah sks.

e. Membantu menyelesaikan masalah-masalah studi mahasiswa, antara lain mencari solusi, memotivasi dan mengarahkan bidang minat yang diinginkan.

f. Mengingatkan mahasiswa agar memantau rekapitulasi kehadiran di unper.ac.id agar mahasiswa tetap mengikuti perkuliahan dengan baik serta memenuhi kehadiran.

g. Mensosialisasikan beberapa ketentuan perkuliahan seperti alasan ketidak hadiran dalam kuliah yang dianggap hadir hanya sakit dengan surat dokter atau surat tugas dari Universitas atau Fakultas dan dikomunikasikan ke petugas di Fakultas.

2) Pada Saat Sebelum Ujian Tengah Semester

Aktivitas yang dilakukan mencakup:

a. Mengidentifikasi permasalahan yang muncul dalam perkuliahan

b. Memantau kehadiran mahasiswa dan melakukan saran tindakan koreksi pada mahasiswa agar dapat memenuhi jumlah kehadiran.

c. Memberi motivasi untuk mempersiapkan Ujian Tengah Semester

d. Mengingatkan mahasiswa tentang memahami tata tertib ujian.

3) Pada Saat Evaluasi Sebelum Ujian Akhir Semester.

Aktivitas yang dilakukan antara lain adalah:

a. Memberi pengarahan dan motivasi terkait persiapan Ujian Akhir Semester.

b. Melakukan evaluasi tingkat kehadiran dan kendala kendala yang dihadapi selama satu semester untuk perbaikan belajar semester berikutnya.

c. Mengingatkan mahasiswa untuk melakukan registrasi (membayar SPP dan KRS online) tepat waktu pada semester berikutnya.

Pertemuan sewaktu-waktu dapat dilakukan dengan tatap muka atau menggunakan media komunikasi (menu pesan atau lainnya yang disepakati dengan dosen wali) jika dipandang perlu oleh mahasiswa atau dosen pembimbing akademik terhadap proses pembelajaran.

\subsubsection{Hak-hak dan kewajiban mahasiswa dalam pembimbingan}

\section{Hak Mahasiswa}

1. Mendapatkan bimbingan dalam merancang mata kuliah yang ditempuh dengan memperhatikan jumlah sks dan IP yang diperoleh sebelumnya.

2. Mendapatkan penjelasan tentang sistem pendidikan di Fakultas/Program Studi

3. Mendapatkan bimbingan jika mendapat IP rendah dalam belajar selama studi berlangsung.

4. Mendapatkan motivasi dalam mengembangkan kreativitas berdasarkan kompetensi mahasiswa

5. Mendapatkan waktu bimbingan, khususnya pada masa perwalian.

\section{Kewajiban Mahasiswa}

1. Mahasiswa diwajibkan membawa buku pembimbingan, pada saat berkonsultasi dengan dosen pembimbing akademik.

2. Menuliskan, permasalahan dan manfaat pada daftar konsultasi

3. Mahasiswa wajib menemui/berkonsultasi dengan dosen wali minimal 3 kali dalam satu semester pada saat: Sebelum KRS on line, Sebelum UTS, Sebelum UAS. Konsultasi dengan dosen wali secara online menggunakan jalur yang disepakati bersama dosen wali.

\subsection{Perancangan}

Pada tahap perancangan dilakukan pembuatan desain sistem yang akan dibangun. Desain yang dibuat terdiri dari diagram konteks, Data Flow Diagram (DFD), Entity Relationship Diagram (ERD).

\section{1) Diagram Konteks}

Diagram konteks merupakan desain umum dari sistem yang akan dibangun dengan integrasi user mahasiswa dan dosen seperti pada gambar 4.1 berikut

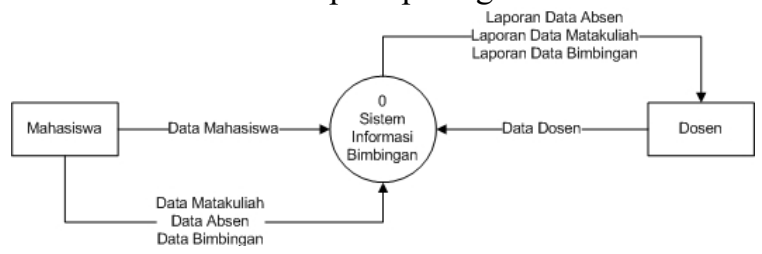

Gambar 4.1. Diagram Konteks

Akses mahasiswa pada data mahasiswa, data matakuliah, data absen dan data bimbingan. Sedangkan akses dosen pada data dosen dan mendapatkan laporan data absen, laporan data matakuliah dan laporan data bimbingan.

\section{2) Data Flow Diargam (DFD)}

Data Flow Diagram merupakan pengembangan dari diagram konteks yang memuat detil dari setiap proses yang ada pada sistem seperti pada gambar 4.2. pada gambar berikut dijelaskan detil akses dosen, mahasiswa dan admin serta integrasi dengan database. Pada DFD 
level ini memuat manajemen login, manajemen master data, manajemen user, manajemen bimbingan dan laporan serta integrasinya dengan database.

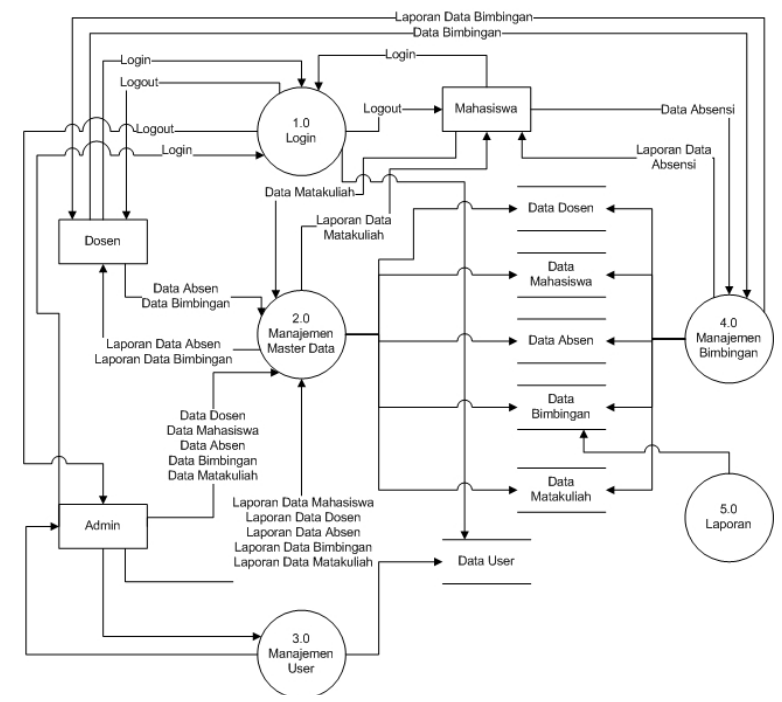

Gambar 4.2. Data Flow Diagram (DFD)

\section{3) Entity Relationship Diagram (ERD)}

Pada desain ERD memuat hubungan antar data dalam kesatuan database. Pada setiap data memuat atribut atribut yang terdapat primary key sebagai atribut kunci dalam pemanggilan data serta foreign key sebagai penghubung antar data seperti pada gambar 4.3 yang menjelaskan relasi antar data. Data mahasiswa dan data dosen berelasi dengan data user, data bimbingan dan data absen. Data bimbingan berelasi dengan dengan data matakuliah data absen.

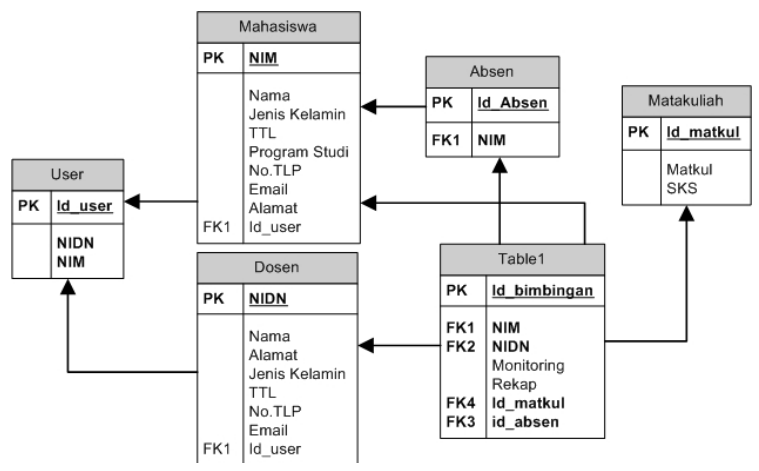

Gambar 4.3. Entity Relationship Diagram (ERD)

\subsection{Implementasi}

Tahap implementasi sistem merupakan proses pengubahan sistem yang telah dirancang pada sebelumnya menjadi sistem yang dapat dijalankan. Sistem Informasi Pelayanan Akademik Universitas Pejuangan Tasikmalaya ini memerlukan perangkat lunak (software) dan perangkat keras (hardware) dalam pembuatannya agar sistem dapat berjalan sesuai dengan yang diharapkan.
Untuk dapat menjalankan Sistem Informasi Pelayanan Akademik Universitas Pejuangan ini dapat langsung di jalankan di semua browser. Sesuai dengan perancangan sistem yang telah dikemukakan sebelumnya pada pembuatan sistem informasi ini terdapat dua tingkat user yaitu pengunjung atau user, dan administrator.

\subsubsection{Halaman Utama Website}

1) Halaman Beranda

Halaman ini merupakan halaman yang pertama kali ditampilkan saat user membuka website Pelayanan Akademik Universitas Perjuangan melalui web browser. Halaman awal berisi halaman login yang dapat ditampilkan dalam website. Pada halaman ini juga terdapat link menuju halaman register untuk user baru.

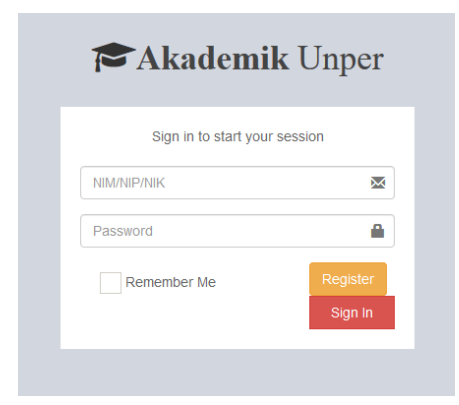

Gambar 4.4. Halaman Awal

\section{2) Halaman Register}

Setelah masuk dalam halaman awal, klik pada menu Regisiter pada website Pelayanan Akademik Universitas Perjuanngan, maka akan muncul halaman baru yaitu halaman Register. Halaman ini juga terlink kembali ke halaman login Pelayanan Akademik Universitas Perjuangan .

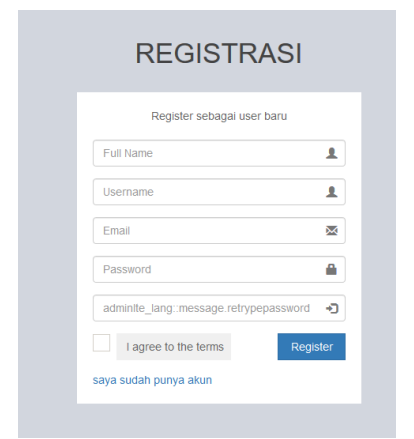

Gambar 4.5. Halaman Registrasi

\section{3) Halaman halaman Beranda Dosen}

Pada menu ini menampilkan halaman Monitoring Mahasiswa dan daftar Mahasiswa Wali. 


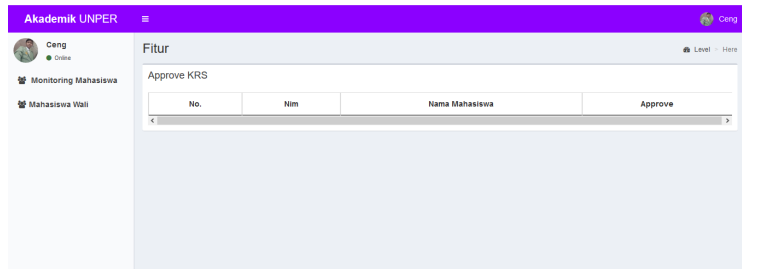

Gambar 4.6. Halaman Beranda dosen

\section{4) Halaman Monitoring Mahasiswa}

Pada menu ini menampilkan halaman dimana dosen bisa melakukan bimbingan dengan Mahasiswa

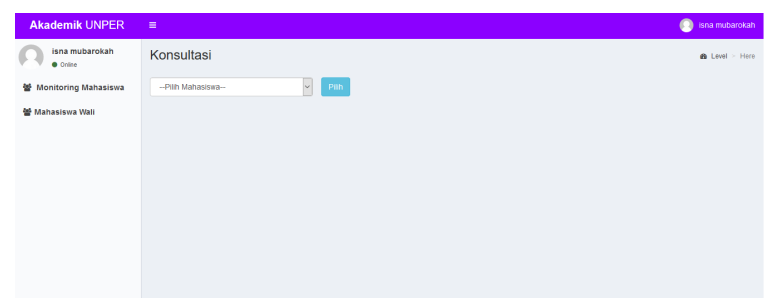

Gambar 4.7. Halaman Monitoring Konsultasi

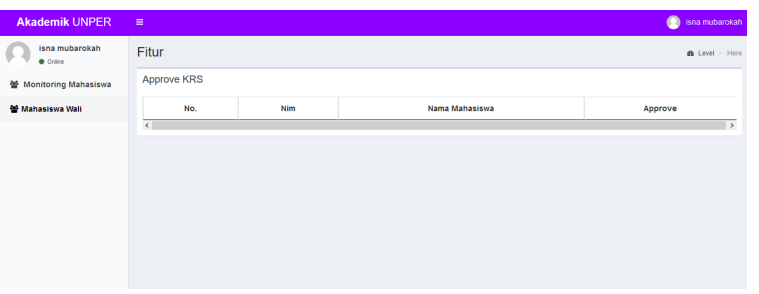

Gambar 4.8. Halaman Mahasiswa wali

\section{KESIMPULAN}

Sistem informasi layanan bimbingan akademik berhasil di rancang dan dibangun menggunakan bahasa pemrograman $P H P$ dan pangkalan data $M y S Q L$.

\section{DAFTAR PUSTAKA}

[1] E. Wahyuni, J. Nurihsan, and S. Yusuf,

"Kesejahteraan Mahasiswa: Implikasi Terhadap Program Konseling Di Perguruan Tinggi," Insight J. Bimbing. Konseling, vol. 7, no. 1, pp. 96-106, 2018.

[2] H. E. Putro and S. Sugiyadi, "Peningkatan Motivasi Belajar Melalui Layanan Bimbingan Kelompok Dengan Teknik Self Regulated Learning," JBKI (Jurnal Bimbing. Konseling Indones., vol. 3, no. 1, p. 1, 2018.

[3] H. Pranoto, "LAYANAN BIMBINGAN KELOMPOK DENGAN TEKNIK SELFMANAGEMENT," vol. 2, no. 1, pp. 87-112, 2018.

[4] N. Norhikmah, "Perancangan Sistem Informasi Monitoring Dosen Wali Menggunakan ASP.NET Signal R," Creat. Inf. Technol. J., vol. 3, no. 3, p. 171, 2018.

[5] I. Ifdil and Z. Ardi, "Konseling Online Sebagai
Salah Satu Bentuk Pelayanan E-konseling," $J$ Konseling dan Pendidik., vol. 1, no. 1, p. 15, 2018.

[6] M. N. Riswandha and N. Maulidyah, "Aplikasi E-Counseling Dalam Pemanfaatan Layanan Bimbingan Dan Konseling Untuk Mengatasi Siswa Terisolir Menggunakan Metode Backward Chaining," J. Link, vol. 26, no. 1, pp. 18-23, 2017.

[7] F. S. Handayani and M. P. Putri, "Perancangan Basis Data Instrumen Bimbingan Konseling Alat Ungkap Pemahaman Diri Siswa," Creat. Inf. Technol. J., vol. 4, no. 2, p. 128, 2018.

[8] E. Noviana, O. Kurniawan, and M. N. Huda, "Pengembangan Aplikasi Tugas Akhir Mahasiswa Berbasis Website Pada Program Studi Pendidikan Guru Sekolah Dasar FKIP Universitas Riau," J. Prim. Progr. Stuidi Pendidik. Guru Sekol. Dasar Fak. Kegur. dan Ilmu Pendidik. Univ. Riau, vol. 7, no. 1, pp. 112, 2018.

[9] J. Nasir, "Sistem pakar konseling dan psikoterapi masalah kepribadian dramatik menggunakan metode forward chaining berbasis web," RABIT (Jurnal Teknol. dan Sist. Inf. Univrab), vol. 3, no. 1, pp. 37-48, 2018.

[10] B. Mulyatno and Z. D. Febriani, "PROTOTIPE PENGEMBANGAN SISTEM APLIKASI BIMBINGAN DAN KONSELING MAHASISWA UNIVERSITAS ISLAM ATTAHIRIYAH MENGGUNAKAN PENDEKATAN MODEL DIAGRAM ALIR DATA," vol. 4, no. 2, 2018.

[11] A. A. Sofyan et al., "Aplikasi Media Informasi Sekolah Berbasis SMS Gateway Dengan Metode SDLC ( System Development Life Cycle )," vol. 6, no. 2, 2016. 